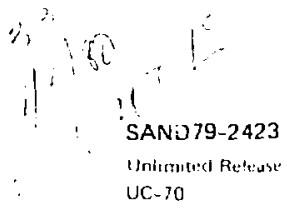

\title{
Bith \\ Mineralogical Aspects of Fluid Migration in the Salt Block || Experiment
}

Steven J. Lambert

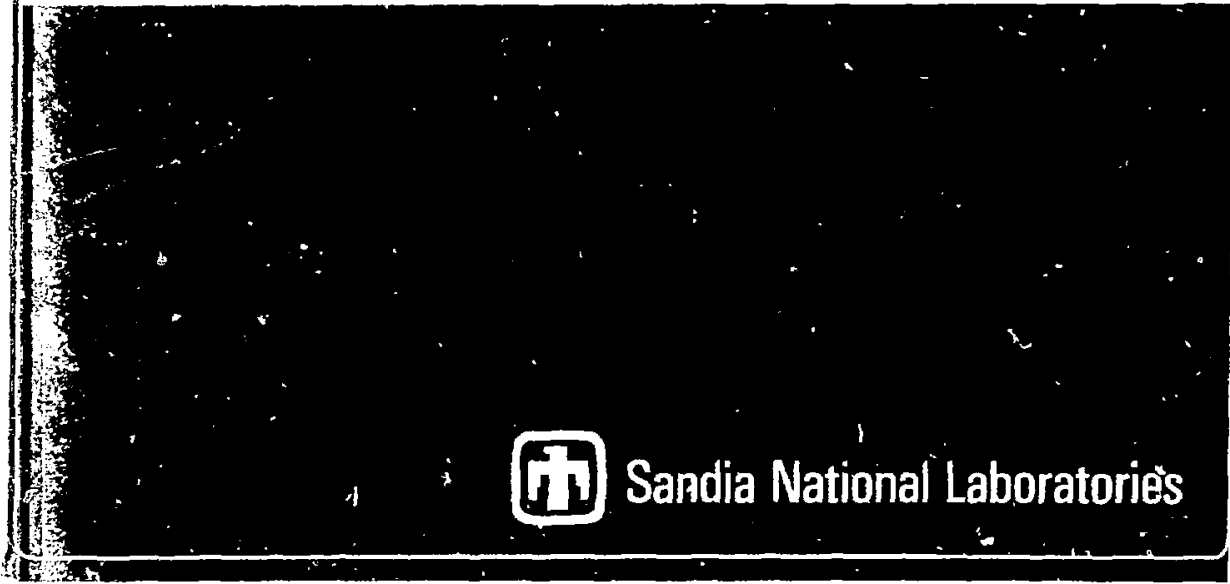




\begin{abstract}
A block of evaporite rock containing the mineral assemblage halite (B8) polyhalite (89) . syluite (49) was machined into a cylinder one meter in diameter and one meter high, and was fitted with an axial heater, themocouples and an ott-gas collection system. After about 100 days of heating, identitication of mineral eftlorescences at the heater hole (carnallite and bischotite) showed that a signiticant portion of the 111 grams of water recovered fout of around 8500 grams available in the rock) migrated as a liquid, not as .a vapor. A migroscoplc examination of rock slices trom within $15 \mathrm{~cm}$ of the heater hole (where the temperature was 100 to $200^{\circ} \mathrm{C}$, and the gradient was 3 to $15^{\circ} \mathrm{C} / \mathrm{cm}$ ) revealed that (1) fluid inclusions had migrated, but racely across grain boundaries, (2) tluid inclusions had not been mobilized at distances greater than about $15 \mathrm{~cm}$ tran the heater hole, and (3) intergranular liquid had been conspicuously mobilized within $15 \mathrm{~cm}$ of the heater hole.
\end{abstract}


TABLE OF CONTENTS

\section{Page}

Introduction ..................... 1

Primary Evaporite Mineralogy . . . . . . . . . . 2

Post-heating Development of Surface Efflorescence. . . . . 2

Post-heating Development of Morphology of Fluid Inclusions . 4

Conclusions .................... 7

Acknowledgement .................. g

References................... 9

Figures (2)

Plates (13)

Distribution 


\section{Introduction}

In 1976, several large blocks of evzpor te rock (about 1 cublc meter each) were quarried from a deift in the wor:ings of the M1ssissipgl Chemlcal Corporation potash mine which is about 18 miles east of Carlsbad, New Mexico. The blocks came from a portion of the 7 th ore zone of the MoNutt member of the Salado Formation (Permian) that is locally poor in poisash (1.e.. syluite-kCl) contant. These blocks were obtained in order to provide evaporite rock in which to conduct experiments designed to slmulate some thermal aspects of heat-generating radioactive waste.

Two of the blocks have been rrachined to a cylindrjcal shape, fitted with an axial heater hole, instrumentation holes, varlous measuring devices, and an exterior metallic sheath, and heated according to a preplanned program. Exper iments involving Salt Block I (Duffey, 1979) were designed to measure primarily the stress state of heated evaporite rock, and secondarily to determine the susceptibility of colspons of various metals to corrosion in the environment afforded by the evapor ite block. Salt Block II (Figure 1), the subject of discussion here, was equlpped wath a hermetically-sealed sheath, a water-vapor collection system, and temperature and heat-flux guages. Thus, an opportunity was provided to observe the rate of devolatillzation of the evaporite rock in response to heating by the axial element. Out of an evaporite mass of about $2700 \mathrm{~kg}$, around $8.5 \mathrm{~kg}$ of whlch was water in various occurrences (estimated on the basis of data of hohlfelder, :979; 1980), 111 grams of watervapor condensate was recovered during the four month experiment. The maximum temperature experienced near the heater was around $200^{\circ} \mathrm{c}$, with a maximum gradient of around $15^{\circ} \mathrm{c} / \mathrm{cm}$.

Design, fabrication and history of the latest experiment ace desrribed in separate discussions (Hohlfelder, 1980). This work will describe some surficial and interior changes in mineralogy and their relevanse to the understanding of the process and consequence of fluid migration in neated evaporites, particularly with respect to the waste Isolation Pilot Piant.

One of the most readily observable changes in evaporites during heating is loss in mass resulting from escape of water from fluid inclusions, intergranular fluid, or hydrous minerals (Powers et ai., 1978). Fohlfelder and Hadley (1979) have discussed the history of this devolatilization in one-kilogram samples. This report will discuse, the nature of efflorescences and internal changes which appeared on the surfaces of machined evaporites after being 
heated, both for one-kilogram samples and for salt Block II, a 1700-kllogram sample. The source and nature of the water that is released from heated evapor $i$ tes has not been determined, nor have the mechanisma which govern fluid migration in heated evaporites been uniquely identified. Interpretations of phenomena described herein will emphasize the definition of the relative importance of various hypothesized mechanisms.

\section{Primary Evaporite Mineralogy}

since evaporites are stratified chemical precipltates which in the northein Delaware Basin have been moderately recrystallized, slgnificant mineralogical variations are commonly observable even in a stratigraphic thickness of a few centimeters. Consequent $2 y$, a hand sample (a one-kilogram cylinder for example) of Salt Block II cannot be taken to be representative of the whole cubic meter. A visual survey of the exterior surface of the machined Salt Block II indicates about 888 halite, 48 sylvite, and 88 polyhalite. One small (kilogram) cylindeical sample, taken before machining of the large block, consisted of 93 halite and 78 sylvite, another was 908 halite, 68 polyhalite and 48 sylvite. The polyhalite in the second small cylinder was preferentially concentrated in a band about $2 \mathrm{~cm}$ wide parallel to the cyllndrical axis. Similarly polyhalite occurs in bands (coincident with bedding) normal to the axis of the cylindrically-machined Salt Block II. Syivite and polyhalite also occur in uniformly-dispersed irregularly-shaped blebs $1 / 2$ to $2 \mathrm{~cm}$ across for sylvite and 1 to $3 \mathrm{~cm}$ across for polyhalite.

These mineralogies are not representative of storage horizons proposed for waste emplacement in the wIPP bedded evaporites.

\section{Post-heating Development of Surface Efflorescence}

Various kinds of machined evaporite samples, large and small, each exhibited post-heating mineralogical changes on the processed surfaces. All samples showed derelopment of mineral encrustations containing water soluble phases, some of which are not known to occur in the original evaporite. The morphology of the encrustations varied from powdery white patches flus.s with the original surface (illustrated in plates 1 and 2), to a bulbous protrusion from the surface (Plate 3 ). The former type of efflorescence was observed on cylindrical exteriors of all the heated samples, but the latter type formed on 
the cylindrical inter lor of the axial heater hole in salt Block II. All efflorescences were white in color, as opposed to the yellow-orange, red-orange and greenish-gray of the original clays and hematitic halite, polyhalite and sylvite.

Samples of the white efflorescences were hand-scraped from the machined surfaces and their mineralogy determined by $x$-ray diffraction. care was taken to exclude primary minerals from the scrapings, but some primary halite was commonly lmavoidably included in the scraplngs, and appeared in the diffractograms.

Most notable among the efflorescences inside the heater hole (Plate 3 ) was the accurrence of carnallite (KMg Cl${ }_{3} \cdot 6 \mathrm{H}_{2} \mathrm{O}$ ). This mineral is not known to occur in the portion of the McNutt potash zone occupied by the Mississippi Chemical corporation mine. Efflorescences dominantly of carnallite were also sampled $f$ rom the exterior of small (1-kilogram) cylinders of similar rocksalt heated in an oven to $260^{\circ} \mathrm{C}$ (Hohlfelder and Hadley, 1979). It is important to nuce also the occurrence of bischofite $\left(\mathrm{Mg} \mathrm{Cl}{ }_{2} \cdot{ }_{6 \mathrm{H}_{2}} \mathrm{O}\right)$ in the mineral matter which encrusted the interior of the bellows seal above the heater hole in Salt Block II. Based on freezing stage studies of fluid inclusion studies of Salado halite, the liquid native to the evaporites as fluid inclusions is not a simple solution of $\mathrm{NaCl}$, but must contain at least $\mathrm{Mg}^{++}$and possibly $\mathrm{K}^{+}$(Roedder and Belkin, 1979). The only non-aqueous source of magnesium in Salt Block II material is the mineral polyhalite $\left(\mathrm{Ca}_{2} \mathrm{~K}_{2} \mathrm{Mg}\left(\mathrm{SO}_{4}\right)_{4}-2 \mathrm{H}_{2} \mathrm{O}\right)$, which dissolves incongruently to give a residue of calcium sulfate. This dissolution, however, liberates magnesium into solution as a sulfate, not as a chloride, and the source for at least the magnesium in the encrustations must be agueous chloride, probably in the fluid native to the rock.

Efflorescences on the exterior (cooled) surface (Plates 1 and 2) occurred along grain boundaries adjacent to patches of opague. flesh-colored polyhalite. These encrustations were composed mostly of recrystallized polyhalite. Another phase was tentatively identified as leightonite $\left(\mathrm{Ca} 2 \mathrm{~K}_{2} \mathrm{Cu}\left(\mathrm{SO}_{4}\right)_{4} \cdot 4 \mathrm{H}_{2} \mathrm{O}\right)$ from a set of weak diffraction maxima, and could have arisen as a product of incipient corrosion of the outer metallic sheath, with copper partially substituting for magnesium in the recrystallized polyhalite.

The presence and absence of certain mineral phases in the efflorescences allows constraints to be placed the nature and role of the fluids which produced them. First, their mother-liquor was probably the aqueous solution 
native to the rock, as intragranular fluid inclusions, intergranular solution, or both. Preliminary analyses (flameless atomic absorption) gave the following approximate ratios of ionic molality in a sample of fluid inclusions: $\mathrm{K} / \mathrm{Na}=0.5, \mathrm{Ng} / \mathrm{Na}=1.25, \mathrm{Ca} / \mathrm{Na}=0.1$. This solution resembles a potash mine seep in solute content (Lambert, 1978). Second, there is no evidence for large proportions of soluble calcium in the mother-liquor, contrary to the suggestion of Roedder and Belkin (1979). In addition, there would be no basis for the formation of calcium-rich liquids of extremely low vapor pressure, as proposed by Stewart, and Potter (1979). Third, at least some of the water (collected as steam condensate) released upon heating of the block appeared at the heater hole as liquid solution, not entirely as a vapor as proposed by flohlfelder and Hadley (1979).

\section{Post-heating Development of Morphology of f'luid inclusions}

Following the unsheathing of the large salt block it was sliced normal to the axis of the heater, and slabs were cut 5 to :.s mm thick from the central portion in the $20 \mathrm{~cm}$ nearest the heater and polished to provide transparency for microscopic examination. See Figure I for approximate location of sample slabs. The primary texture and mineralogy of the original rocksalt were largely preserved without conspicuous recystallization. The elongation of sluid inclusions in a direction radial to the heater hole, was the most noticeable change which occurred upon heating of the rocksalt. Polyhalite was unalterec since its dehydracion temperatuie $\left(>300^{\circ} \mathrm{C}\right)$ was not achieved.

The fluid inclusions were observed most clearly in halite, there being but few in the less-abundant sylvite, and polyhalite being opaque. plate 4 shows some morphologies which developed in the hrated Salt Block II, Notable are the "nailheads" and "walking-stick heads" (Plates $4 \mathrm{a}$ and $4 \mathrm{~b}$, respectively) developed at the heated ends of the elongate fluid inclusion tracks. Plate $4 b$ also illustrates the abandorment of inclusion material in the tail portion by "necking down" of the elongate track, which may give rise to "string-of-beads" form if connections persist. It is iot known whether development of bulbous "hot" ends is an equilibrium feature, independent of local crystallography, or is a transient feature, presecved during the cooling phase of the experiment. Plate 5 shows fluid iriclusion tracks within $6 \mathrm{~mm}$ of the heate hole. A bound. ary between halite grains occurs one-third of the way from the top of the 
plate. The large track in the upier left appears to have deviated upon encounter with the grain boundary. while analle- incluslons initlale or terminate at or near the boundary.

Plate 6 shows portions of a boundary containing small grains of polyhalite. The well-defined spindle-shaped inclusion (Plate 6a) terminates, while the irreqular track appears to pass through the boundary. In same places, nailheads have developed very near the boundary (Plate 6b). These observations appear to reinforce the conclusion of Roedder and Belkin (1979) that only the larger inclusions tend to cross the grain boundaries during migration up the thermal gradient.

A systematic visual (microsopic) examination of pollshed slices of rock adjacent to tihe heater hole revealed a zonation of phencmena resulting fran perturbation of the evaporite rock by the thermal and stress fiel as, hereafter called the "perturbed zone." Aside $E$ rom the occurrence of recrystaluized polyhalite (Plates 2 and 3), which is probably a thermal rather than a thermal gradient effect, most of the conspicuous perturbations occurred within $15 \mathrm{~cm}$ of the heater hole. Plates 7 through 13 are a graphic docunentation thereof. Figure 2 shows approximate profiles of maximum temperatures and temperature gradients experierced by the sliced samples (see George, 1980).

At the outer periphary of the "perturbed zone," the intragranular fluid inclusions (see Roedder and Belkin, i979, for an extensive description) are virtualiy intact. Just within the $15 \mathrm{~m}$ radius fram the heater hole, however, are a series of subanriular textural eienents (Plate 7) that have Iittle relationship with original grain Doundarias, fluid inclusions or beting. As is the case with all of these post-heating microsopic observations, the time of occurrence of these features ir. the course of the experiment is not obvious. These features appear to be fractures with onlv a few microns of open space, and the fact that annealing of the halite has not occurred (nor has recrystallization) suggests that fracturing occurred late in the experiment, probably in the cooling phase, when mechanical contraction would be expected to place the cooler, more brittse portions of the rock in tension.

In the zone within about 11 on of the heater tole, incipient changes in fivid inclusi on mor phology are evident. Plate 9 illustrates a morphology common in the periphery of the perturbed zone. This general shape, a "bullet head" pointing toward the heat source, and several "tails" pointing away, is 
characteristic of the laiger accumulations of intragranular Eluid (more than $1 \mathrm{~mm}$ across). Similar shapes were noted by Anthony and cline (1971) in sylvite and by Roedder and Balkin (1980) in hallte. As in the case of the latter citation, it is not known "whether this shape developed early in the run and represents a dynamic equilibrium shape or whether it was still in the process of evolving at the end of the runs." Mlevertheless, the phenomenon occurs only in the halite in a zone about 7 to $11 \mathrm{~cm}$ from the heater, and only in larger inclusions.

Within the peripheral perturbed zone, another phenomenon conspicuously developed is the alteration of morphology of fluld accumulation along grain boundaries. Whereas plate 8 depicts undisturbed fluid at grain boundary, fluid at the boundary illustrated in Plate 10 has coalesced into large "droplets," which have become elongated parallel with the temperature gradient. The fact that this component of free fluid has become mobilized in a zone in which only the larger intragranular inclusions have moved (Plate 9) suggests that gra:-bounäary water may be a more significant contrlbution to mobile fluids than heretofore recognized. The model proposed by Hohlfelder and Hadley (1979) has treated the mechanism of fluid migration in evagorite blocks as porous flow. That part of the model may indeed nut be far from correct, although transport entircly as vapor cannot in any way account for the observer mineralogical changes.

In the zone very near (less than $4 \mathrm{~cm}$ ) the heater hole, elongate intragranular inclusions are common, many of which contain bubbles. Most of these inclusions are elongated parallel with the temperature gradient (Plate 11), but a significant number of them are elungased at right angles to it (Plate 12). Inclusions in this zone appear to be bounded at least in part by faces of cubic crystal forms. These inclusions have not discharged their liquid contents. "Gradient-parallel" elongate inclusions (Plate ll) appear to be composed of accumulations of fluid intermediate in volume between the large "octopus" forms (Plate 9) and those elongated perpendicular to the gradient. According to Roedder and Belkin (1980) flattened inci'lsions tended to move faster than elongate ones. Conversely, the same work reported a much higher rate of movement for larger inclusions. If direction of elongation is realted to size (and therefore rate of movemenc) is it not obvious how the two foregoing statements can be reconciled in the face of these osservations. 
The protusion of gmall inelusions wichin $4 \mathrm{~cm}$ of the heater hole could be atcributed to: (1) the breakup or larger, taster isclusions, (2) the convergence or a given amount of tluid from an annular volume of rock into a gmaller annular volume, or (3) a hlgher Initial concentration of tluid near the heater hole. In any case, the larger, supposedly taster inclusions ( $P 1$ ate 9) have not compleied their journey, but stopped at least $7 \mathrm{~cm}$ tram the beater mole. Evidence of escape of tluid trom intragranulic inclusions was found only in the I cm nearest the heater Ir (Plate 13). Hece, as illustrated belore, inclusions have developed irregular tiacks, with hailheads and strirgs-otbeads. As can be seen, many inclusion tracks terminate at the heater hole.

\section{Corclusions}

photomicrographic observations have indicated that the 111 grams of water (out of about $8 \mathrm{kilograns}$ avallable) released in about 100 days tran the 2-metruc-ton salt Block II dia not originate primarily trom intragranular tluid inclusions, which are volumetrically by $f$ at the most important contribution to the total water present in the evaporite. Etflorescences encrusting the interior or the axial heater hole are composed ot phasas not present in the original rock. These phases, and their carrier $t 1$ uid, could not have migrated in the vapor phase. The encrustations represent solutes in the aqueous phase in the rock, and consist of chlorides of sodium, potassium and magnesium, but not calcium. The most protaund textural changes were obser ved within $15 \mathrm{~cm}$ of the trater hole, but even within this region $\left(\mathrm{I}^{\prime}>100^{\circ} \mathrm{C}, 0 \mathrm{~T}>3^{\circ} \mathrm{C} / \mathrm{Cm}\right.$ ) intragranular inclusions have been reluctant to cross grain boundaries. The generally restricted movement or intragranular tluid during the 100-day heating phase is consistent with the low rates of individual intragranular Iluid inclusion movement reported by Roedder and Belkin (1980), about 1 centimeter per year at these temperatures and temperature gradients. The impediment posed by a grain boundary would cause the net rate of intragranular tluid movement to be even lower, it the path of movernent were to traverse several grains. Alternatively, scme of the tluid encountering a grain boundary could become part of the intergranular tluid phase, whose movement would be governed by a ditterent set of mechanisms. The aqueous phase at graln mindaries appears to have been mobilized, and may be the most important mabile moisture source, except within $2 \mathrm{~cm}$ ot the heater. A prerise set of mechanisms tor mobilization of intergrar.ular liguid is not well understood at this time. 


\section{Acknowledgement}

David Helnze performed $x$-ray diféraction analyoes on mineral encruatations. Hugh Sumin cut and polished plates of evaporite rock and extracted fluld from inclusions for analysis. Lial Brewer provided the fluld inclusion analyses by atomic absorption. Henry Shefelbine, William Holser and George Barr provided helpful discussions. 


\section{REFEREACES}

Anthony, T. R., and H. E. Cline, 1971, Thermal wigratfor. of i iyuid aldplets through solids: Jour. Appl. Physics, d. 42, p. 3330-5387.

Duffey, T. A., 1979, Sale Block I test: Exper lmental detalls ano comarison with theory: Sandia National Laboratories, SANo79-7050.

Gearge, 0., 1980, Compister thermal modeling for ths salt Block I experiment: Sandia National Laboratorits, SAND79-2250 (in preparation).

Hohlfelder, J. J., 1979, Measurement of water lost from heated qeologic salt: Sandia National Laboratories, SAND79-0462.

Hohlfelder, J. J., 1980, Salt Block II: Description and re:lults: Sandia National Laboratories, SAND79-2226.

Hohlfelder, J. J., and G. R. Had?ey, 1979, Laboratory studies of L ter transpott in rock salt: Letters on heat and mass transfer, v. 6, p. 271-279.

Lambert, S. J., 1978, the gecchemistry of Delaware Basin rcoundwaters in Gealogy and mineral deposits of Ochoan rocks in Delaware Basin and adjacent areas: New Mxico Bureav of Mines and Mineral Resources, Circ. 159, F. 32-38, 5 'cables, 3 figures.

Powers, C. W., S. J. Lambert, S. E. Silaffer, L. R. Hill, and W. D. Weart (eds.), 1978, Geoloyical characterization renort, waste Isolation Pilnt Plant (WIPP) site, southeastern New Mexico: sandia Laboratories, Albuquerque, New Mexics. SAND78-1596.

Roedder, E., and H. E. Belkin, 1979, Application of studies of fluid inclusions in Permian Salado salt, New Mexico, to problems of siting the Waste Iscidi ion Pilot plant: Scientific basis for nuclear waste management, v. 1, Plenum Press, New York, P. 313-321.

Roedder, E., ant H. E. Belkin, 1980, Thermal gradient migration of fluid inclusions in salt from the Waste Isolation Pilot Plant (WIPF): scientific basis, for nuclear waste management, $v$. 2, in press.

Stewart, D. B., and R. W, Potter, II, 1979, Application of physical chemistry of fluids in rocksalt at elevated temperature and pressure to repositorjes for radioactive waste: Srientific basis for nuclear waste management, v.1., Plenum Press, New York, p. 297-311. 


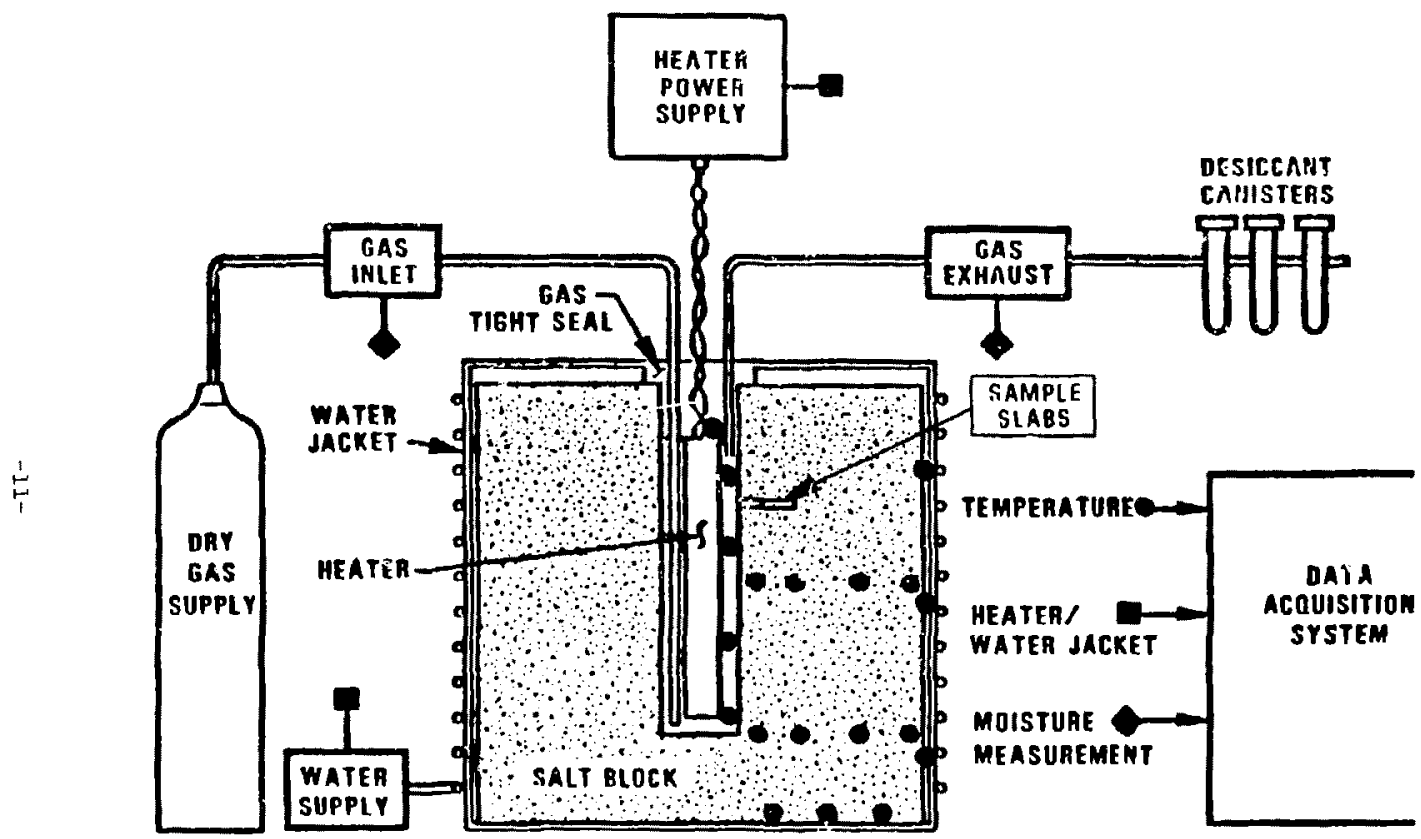

Flqure I STHEMATIC ÖF THE SALT BLOCK II EXPERIMENT

adaptgd frein Hohlfelder [1980] 

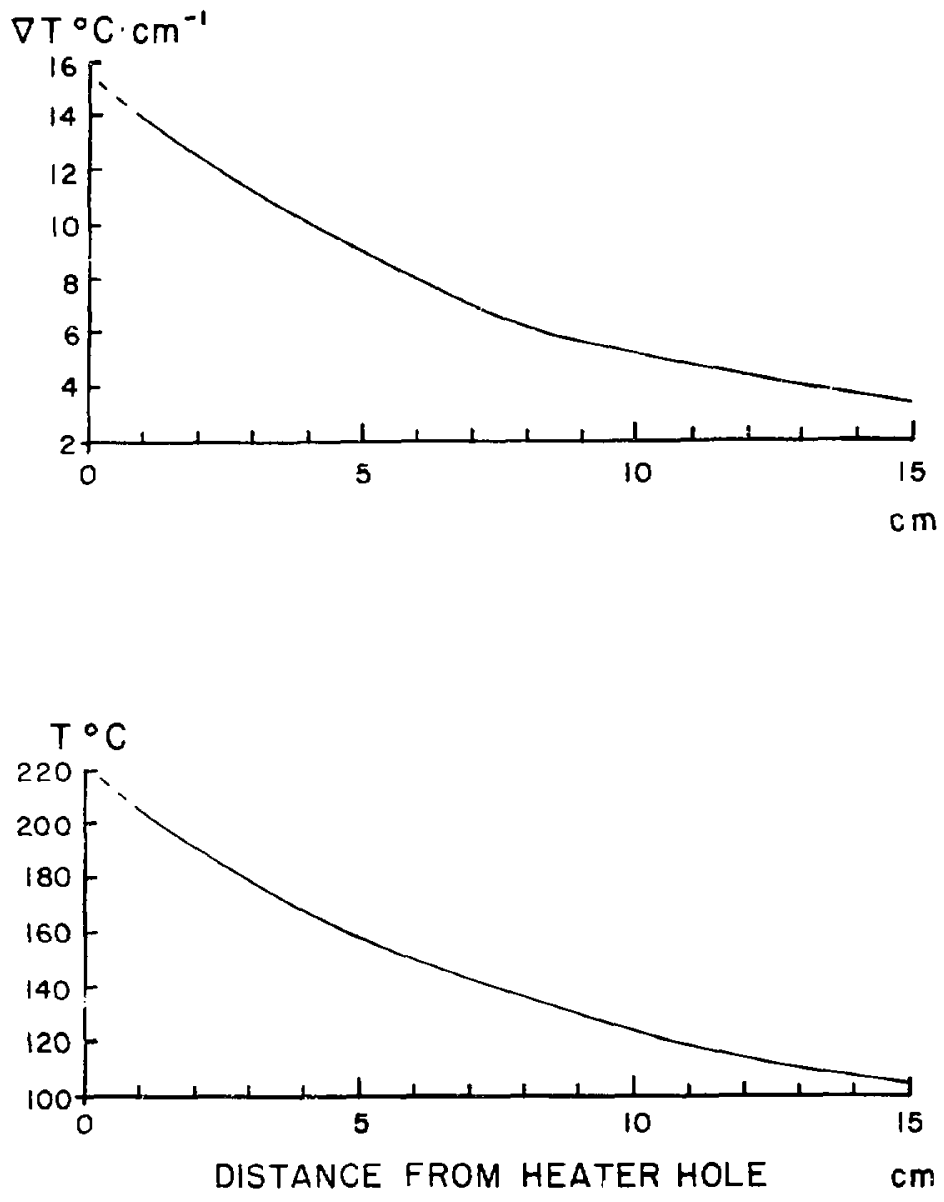

Figure 2. Approximate temperature and temperature gradient as a sunction of distance from heater hole in salt Block II, steady state at maximum heater power, 1.5 kw. After George (1980).

$$
-12-
$$


Plate 1. Interior of axial hole ( 5 inches across) with aheathing in place, showing mineral efflorescences protzuding from the wall (carnallite + halitel. Elongste encruatation follow grain boundaries. Bellows seal (encursted with bischotite + hallte), heater, instrumentation and crushed ceagent-grade NaCl packing have been removed following shutdown of heating and molsture cs!lection.

Plate 2. Outer cylladrical surface of large (1700 kg) block of evaporite rock, showing white efflorescences (rearyctallized polyhalite) in the vicinity of original polybalite, most consplcuously developed alang grain bowndaries.

Plate 3. Outer cylindrical surtace of block of evaporite rock, showing preferred alignment of secondary (white) polyhalite efflorescence. assoclated with a band of original (flesh-colored) polyhalite. The alignment follows the texi.ral (bedding?) trend of the rock, as apparently does the post-leating fracturing (near little fir.ger).

Plate 4. Mor phology of tracks of fluid inclusions in heated rocksalt. Heat source toward left. Scale bar $=500$ microns.

a. "Nailhead" track, shoring flattening normal to temperature gradient..

b. "Walking-stick head" track, show?.; "neckirg down" in tall portion.

c. "String-of-beads" tracks, with local "nallhead" development. shadows cast by polyhalite grains below polished s. f ace.

Plate 5. Relaticniships between tracks of fluid inclusions in heate rocksalt and heat source. A stall arc of the heater-hole wall has been subtencied at the bottom of the photograph. Sca e bar $=500 \mathrm{microns}$. Most tracks are spindle-shaped, orlented normal to the heater-hole wall, with local developnent of nailheads and strings-of-beads. The large inclusion (upper left) encountered and partially crossed a grain boundary. It resumed a more tortuous, bifurcated path slightly belon the polished surface. Other tracks terminate or initiate (upper enter) at the grain boundary.

Plate 5. Relationships between tracks of fluid inclusions and grain boundaries. Heat source toward left. Scale bar = $500 \mathrm{microns}$.

a. Spindle-shaped and irregular tracks terminating at a grain boundary containing polyhalite. Note also the large irregular track in the center transcending the grain boundary.

b. Nailhead development in tracks encountering a boundary between halite grains. This behavior cisld result in a coalescence of fluid along the boundary.

Plate 7. Subparallel curcilinear features developed in halite $13 \mathrm{~cm} f r a m$ the heater hole, which is to the left in this and all remaining photomicrographs. The length of the black scale bars in this and subsequent plates represents 500 miccons. Could these be tensional fractures developed upon cooling, approximately parallel to the cylindrical surface of the heater hole? Note unperturbed fluid inclusions (square outlines, center). 
Plate 8. Grain boundary, approximately parallel to focal plane. Note vermiform patterns of included solution along the boundary, and unperturbed imtragranular fluid inclusions (square out lines) slightly out of focus. Center 18 about $12.5 \mathrm{~cm} f r o n$ heacer hole.

Plate 9. Relatively 1 arge $(>1 \mathrm{~mm}$ fluld I nclusicn, whose shape changed during an undetermined time in the course of the heating experiment, This is but one example of many such inclusions whose leadir.g edge has assumed a blunt point, with several 'stringers" tralling behind. These are found about 7 to $11 \mathrm{~cm} f r a n$ the heater hole.

Plate 10. Another grain boundary, showing vermiform development of inclusions therein, but with a preferred orlentation (radial to the heater hole, about $4 \mathrm{~cm}$ away), as opposed to a more randon arkay in apparently "undisturbed" halite (Flate 8 ).

Plate 11. Fluid inclusions elongated radial to the heater hole, mast containing bubbles, indicating that they still contain fluid. There is thus no indication of ..leir contents' escape into the moisturecollection system, since they are completely contained in halite. These accur about $3.5 \mathrm{~cm}$ from the heater hole.

Plate 12. Int. igrarular fluid inclusions enlongated tangential to the heater nole. about $2.5 \mathrm{~cm}$ away. The elongation is perpendicular to an thetmal gradient known to have existed during the experiment. The local crystallography appears to influence their boundaries as indicated by the square shapes.

Plate 13. Fluid inclusion tracks near the heater hole, whose curvature may be seen at the extreme left edge of the photograph. Note $t$ he development of nailheads and strings-of-beads. This is the only zone in which intragranular inclusions are actually seen to make good their "escape" into the neater hole. 


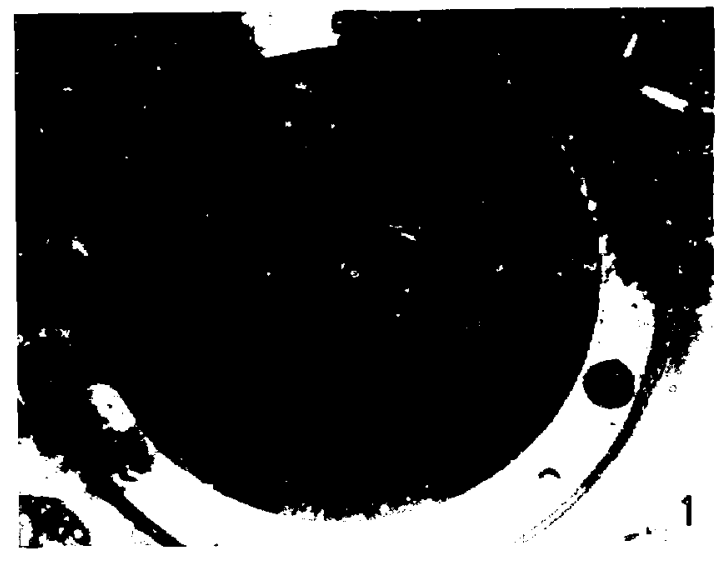

-15- 

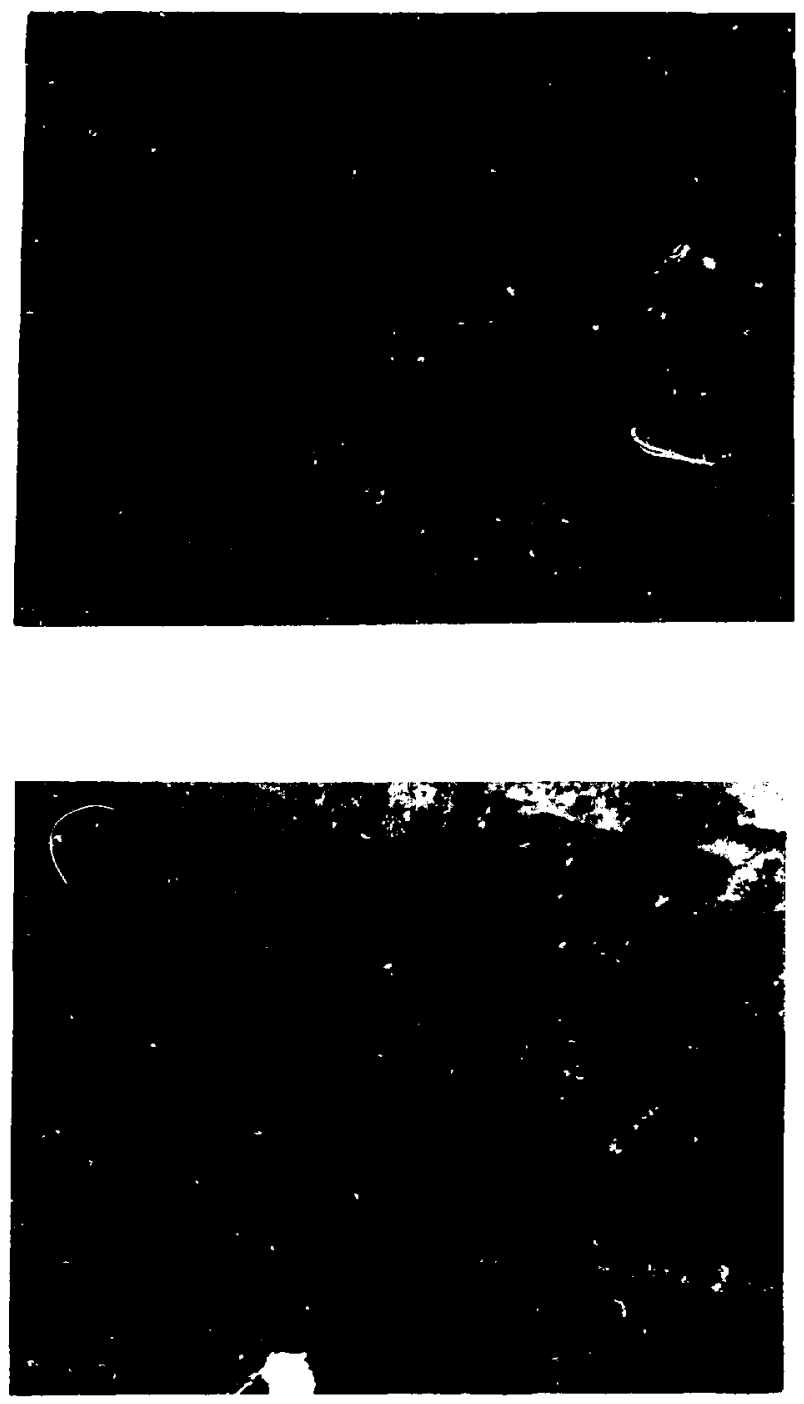

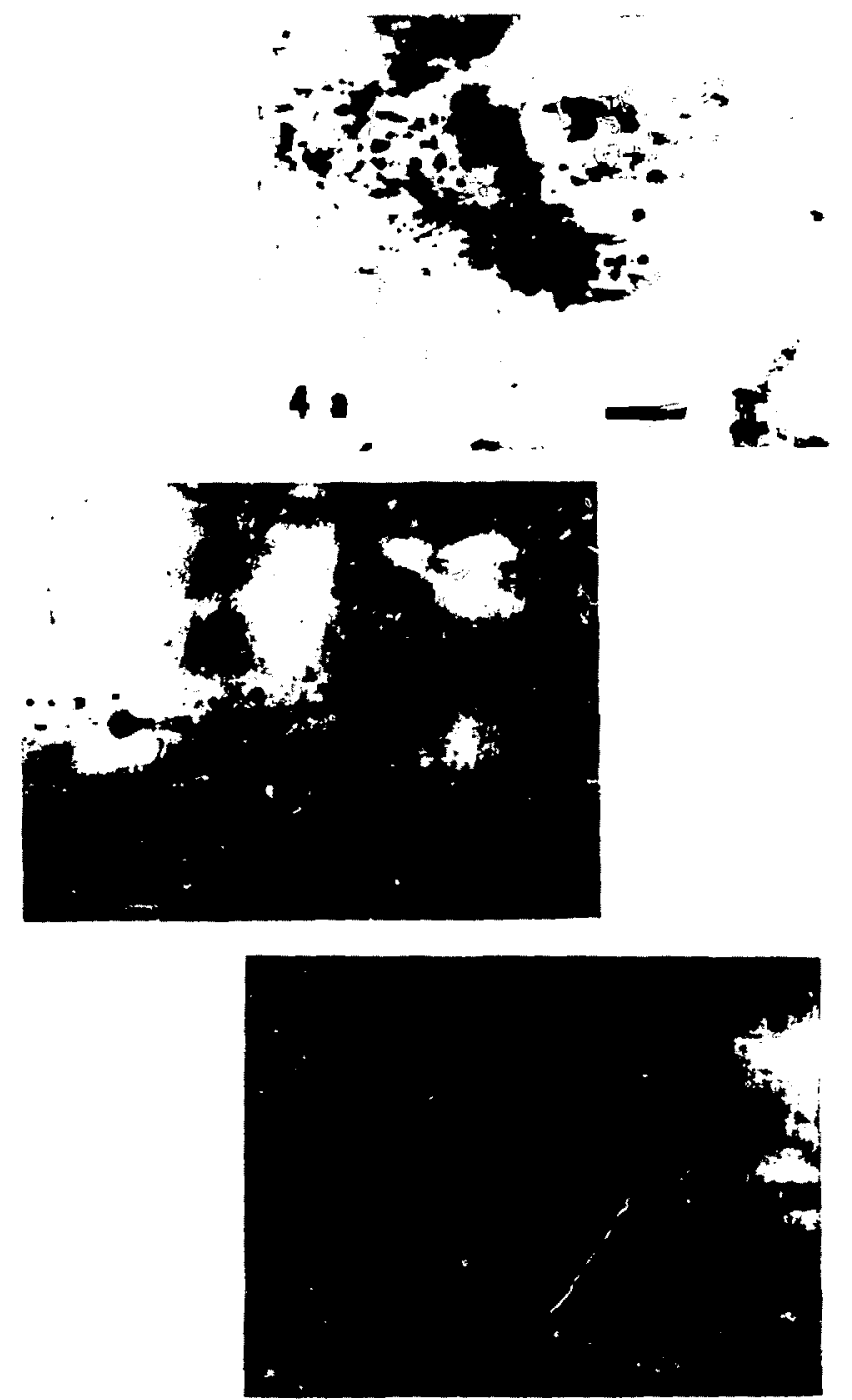

$-17-$ 


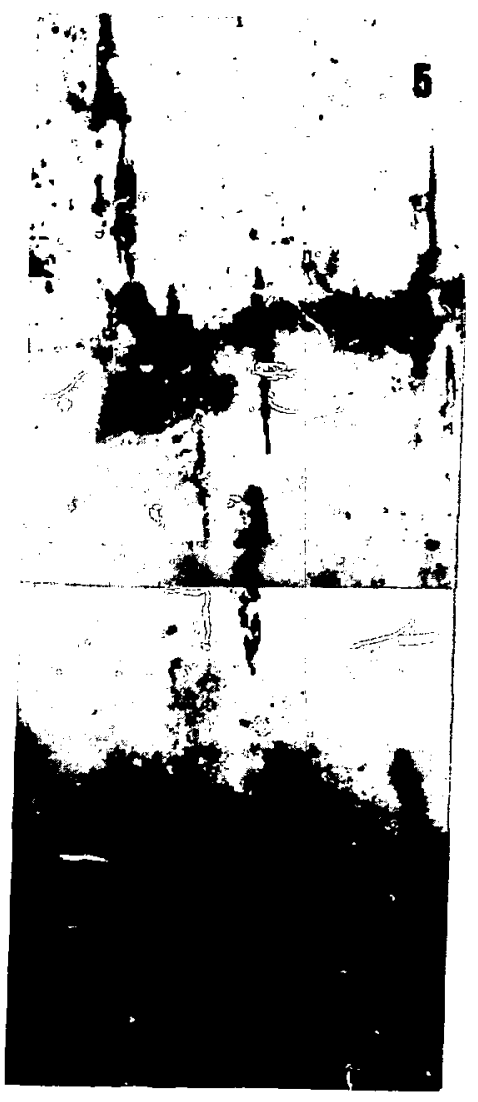



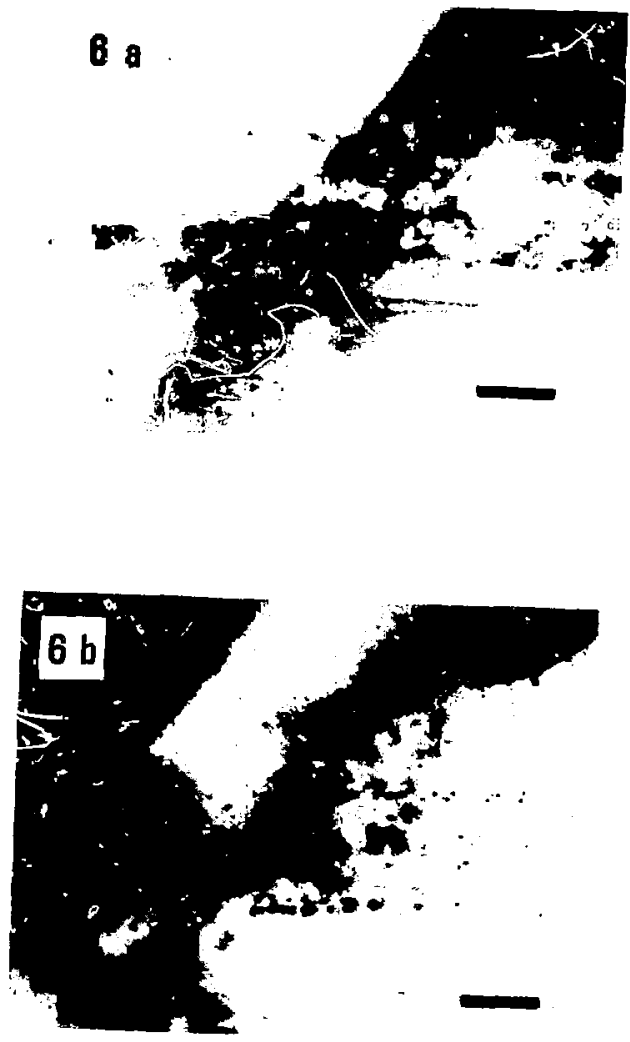

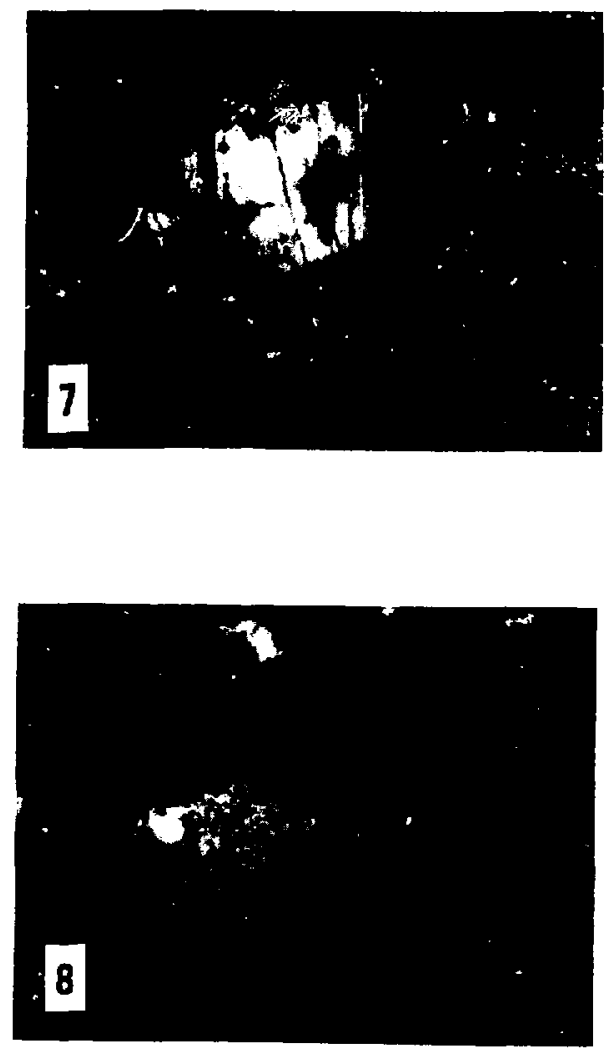

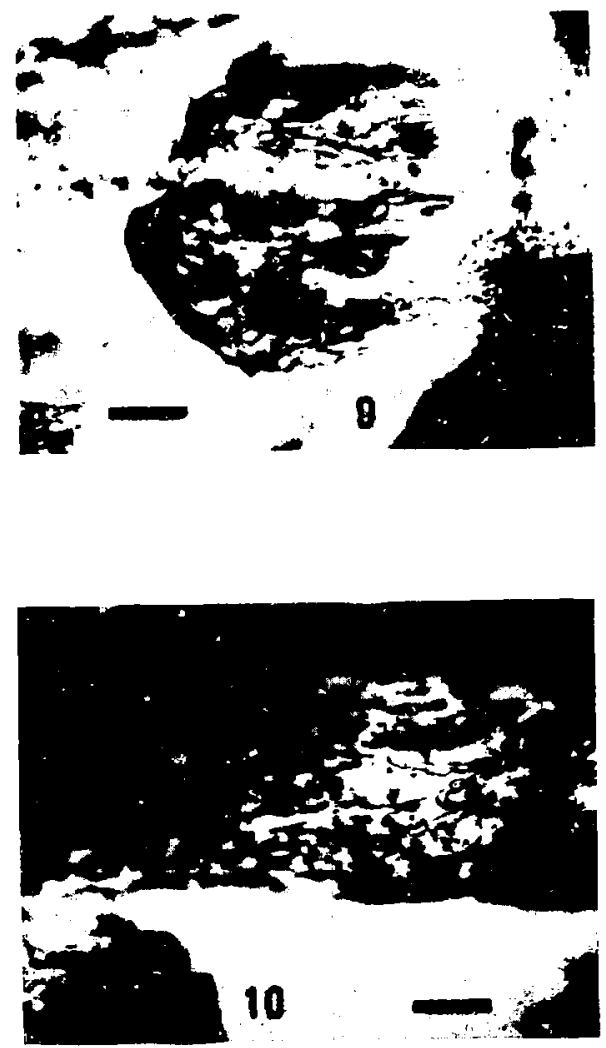

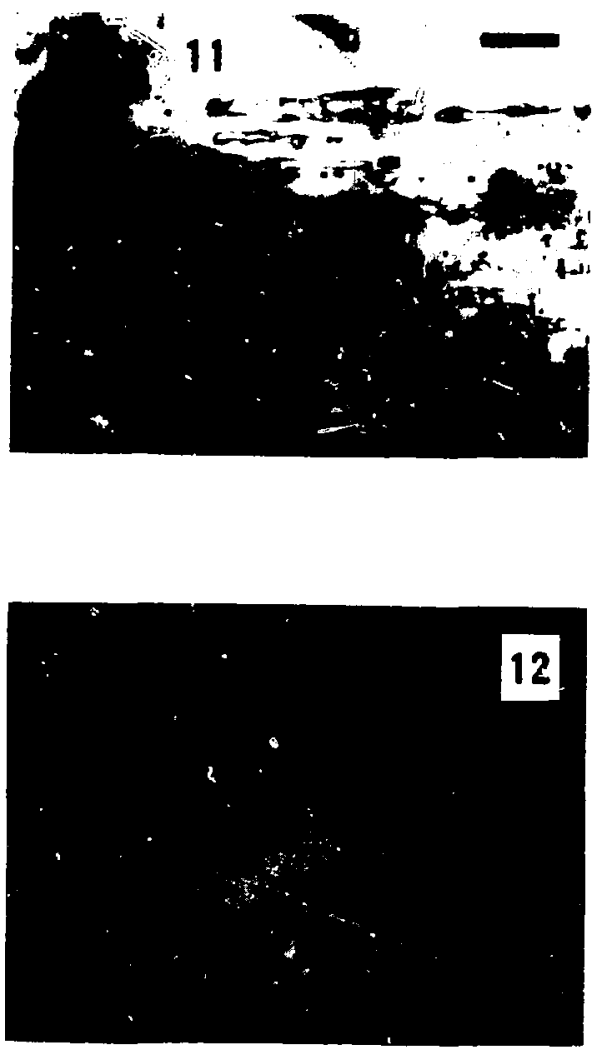

$-22-$ 


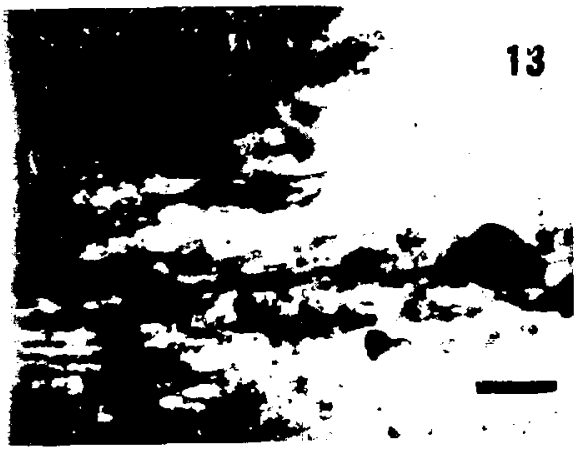

